\title{
Lactose Malabsorption Testing in Daily Clinical Practice: A Critical Retrospective Analysis and Comparison of the Hydrogen/Methane Breath Test and Genetic Test $\left(C / T_{-13910}\right.$ Polymorphism) Results
}

\author{
Dietmar Enko, Erwin Rezanka, Robert Stolba, and Gabriele Halwachs-Baumann \\ Department of Laboratory Medicine, Central Hospital Steyr, Sierningerstraße 170, 4400 Steyr, Austria \\ Correspondence should be addressed to Dietmar Enko; dietmar.enko@gespag.at
}

Received 23 January 2014; Accepted 25 March 2014; Published 16 April 2014

Academic Editor: Peter James Whorwell

Copyright (C) 2014 Dietmar Enko et al. This is an open access article distributed under the Creative Commons Attribution License, which permits unrestricted use, distribution, and reproduction in any medium, provided the original work is properly cited.

The aim of this study was to establish a retrospective evaluation and comparison of the hydrogen/methane $\left(\mathrm{H}_{2} / \mathrm{CH}_{4}\right)$ breath test and genetic test $\left(\mathrm{C} / \mathrm{T}_{-13910}\right.$ polymorphism) results in lactose malabsorption testing. In total 263 consecutive patients with suspected lactose malabsorption were included in this study. They underwent the $\mathrm{H}_{2} / \mathrm{CH}_{4}$ breath test following the ingestion of $50 \mathrm{~g}$ lactose and were tested for the $\mathrm{C} / \mathrm{T}_{-13910}$ polymorphism. In total 51 patients $(19.4 \%)$ had a $\mathrm{C} / \mathrm{C}_{-13910}$ genotype, indicating primary lactose malabsorption. Only 19 patients (7.2\%) also had a positive $\mathrm{H}_{2} / \mathrm{CH}_{4}$ breath test. All in all 136 patients (51.69\%) had a $\mathrm{C} / \mathrm{T}_{-13910}$ and 76 patients $(28.91 \%)$ a $\mathrm{T} / \mathrm{T}_{-13910}$ genotype, indicating lactase persistence. Four patients $(1.5 \%)$ with the $\mathrm{C} / \mathrm{T}_{-13910}$ genotype and one patient $(0.4 \%)$ with the $\mathrm{T} / \mathrm{T}_{-13910}$ genotype had a positive $\mathrm{H}_{2} / \mathrm{CH}_{4}$ breath test result, indicating secondary lactose malabsorption. Cohen's Kappa measuring agreement between the two methods was 0.44 . Twenty patients (7.6\%) with a positive $\mathrm{H}_{2} / \mathrm{CH}_{4}$ peak within 60 minutes after lactose ingestion were classified as patients with lactose-dependent small intestinal bacterial overgrowth (SIBO). In conclusion, only moderate agreement between the breath test and the genetic test was shown. Secondary lactose malabsorption as well as preanalytical limitations of the combined $\mathrm{H}_{2} / \mathrm{CH}_{4}$ breath test procedure can cause discrepant results. This trial is registered with K-42-13.

\section{Introduction}

The disaccharide lactose is synthesized in the mammary gland of mammalians (except the sea lion) and is essential for the nourishment of newborn infants $[1,2]$. In the small intestine brush border the lactase enzyme is responsible for the absorption of lactose [3]. After the ingestion of lactose, the unabsorbable disaccharide is hydrolysed into the monosaccharides glucose and galactose, that are absorbed [4]. If the lactase enzyme activity is inadequate, the unabsorbed lactose will reach the large intestine, where the gut flora ferments the sugar molecules into short-chain fatty acids, carbon dioxide $\left(\mathrm{CO}_{2}\right)$, hydrogen $\left(\mathrm{H}_{2}\right)$, and methane $\left(\mathrm{CH}_{4}\right)[5,6]$. Lactose malabsorption (hypolactasia) exists in three different forms: congenital, primary, and secondary $[3,7]$. The congenital lactase deficiency is an extremely rare autosomal recessive lifelong gastrointestinal disorder, leading to watery diarrhea from the first exposure to breast milk in infants $[2,3,8]$. The primary lactose malabsorption, also known as adult-type hypolactasia or lactase nonpersistence, is the most common phenotype found in humans. This form is inherited autosomal recessive and results in a decline of lactase enzyme activity in the small intestine. A single nucleotide polymorphism $\left(\mathrm{C} / \mathrm{T}_{-13910}\right) 14 \mathrm{~kb}$ upstream from the lactase gene (LCT) locus is associated with the adulttype hypolactasia $[2,3,9]$. The analysis of the $\mathrm{LCT} C / \mathrm{T}_{-13910}$ polymorphism is considered to have a strong concordance with the lactose breath test for predicting lactose malabsorption in European populations [10-12]. The secondary lactose malabsorption is an acquired and reversible form associated with inflammatory bowel disease, celiac and tropical sprue, short bowel syndrome, radiation enteritis, infectious enteritis, gastrointestinal surgery, drugs, or small bowel bacterial overgrowth (SIBO). Lactose malabsorption is 
defined as inefficient digestion due to intestinal pathologies or lactase nonpersistence, whereas lactose intolerance is defined as lactose malabsorption with gastrointestinal symptoms $[5,7]$. The lactose breath test is a widely used diagnostic tool for lactose malabsorption testing. The reliability of this test depends on the activity of the intestinal bacterial flora fermenting undigested lactose and producing $\mathrm{CO}_{2}, \mathrm{H}_{2}$, and $\mathrm{CH}_{4}$. These gases are not only absorbed and eliminated via the lungs but also can cause abdominal pain, bloating, flatulence, and diarrhea $[1,13]$. Only about one-third of the lactose malabsorbers are recorded with symptoms during the breath test [14]. Despite the simple performance of the lactose breath test, the uniformity and standardization of the testing procedure and the test interpretation are still lacking $[6,15]$. SIBO is a heterogeneous syndrome defined as the presence of an increased number and/or abnormal type of bacteria in the small bowel. The true prevalence of SIBO is unknown and depends on the characteristics of the diagnostic method and the study population $[16,17]$. The aim of this study was to analyze the combined $\mathrm{H}_{2} / \mathrm{CH}_{4}$ lactose breath test and genetic test $\left(\mathrm{C} / \mathrm{T}_{-13910}\right.$ polymorphism) results in daily clinical practice and to compare both methods. In addition the diagnosis of lactose-dependent SIBO $[6,18]$ was evaluated based on the combined $\mathrm{H}_{2} / \mathrm{CH}_{4}$ breath test results.

\section{Materials and Methods}

2.1. Ethical Approval. The ethical approval for this study was provided by the Ethical Committee of Upper Austria, Linz, Austria (Trial registration number: K-42-13).

2.2. Patients. This retrospective study was performed at the Department of Laboratory Medicine in the Central Hospital Steyr. A total of 298 consecutive case histories of patients were reviewed. They came to the outpatient clinic from July 1,2007 , to July 31,2010 , to undergo an examination of lactose malabsorption. Inclusion and exclusion criteria were as follows. The inclusion criteria were the parallel performance of the combined $\mathrm{H}_{2} / \mathrm{CH}_{4}$ lactose breath test and the genetic test $\left(\mathrm{C} / \mathrm{T}_{-13910}\right.$ polymorphism) in the above-mentioned period, a twelve-hour overnight fasting, and abstaining from smoking. Patients who have completed antibiotic therapy were excluded for at least four weeks from the breath test. In total 35 patients were excluded from this study because they did not fulfill all the defined diagnostic criteria of the combined $\mathrm{H}_{2} / \mathrm{CH}_{4}$ breath test as listed below.

2.3. $\mathrm{H}_{2} / \mathrm{CH}_{4}$ Breath Test. Gas chromatography was employed to measure the breath $\mathrm{H}_{2}$ and $\mathrm{CH}_{4}$ concentration using the QuinTron Model DP Plus MicroLyzer (QuinTron, Milwaukee, WI, USA). After determining the baseline breath $\mathrm{H}_{2}$ and $\mathrm{CH}_{4}$ concentration, lactose was given in a dose of $50 \mathrm{~g}$ dissolved in $200 \mathrm{~mL}$ of water [10, 19]. The end-expiratory breath $\mathrm{H}_{2}$ and $\mathrm{CH}_{4}$ concentration was measured at $15,30,45$, $60,75,90$, and 120 minutes after lactose ingestion. The results were expressed in parts per million (ppm). During the test the patients were asked to report clinical symptoms and to avoid eating, smoking, and physical effort. The breath test result was considered positive if the $\mathrm{H}_{2}$ and/or the $\mathrm{CH}_{4}$ peak was
TABLE 1: Positive lactose $\mathrm{H}_{2}$ and/or $\mathrm{CH}_{4}$ breath test results.

\begin{tabular}{lcc}
\hline$n=24(9.1 \%)$ & $\mathrm{H}_{2}$ breath test & $\mathrm{CH}_{4}$ breath test \\
\hline$n=21(8.0 \%)$ & + & - \\
$n=2(0.7 \%)$ & - & + \\
$n=1(0.4 \%)$ & + & + \\
\hline
\end{tabular}

+: $>20$ parts per million above baseline during the colon passage (60-120 minutes), -: negative.

$>20$ ppm over the baseline value [20]. Patients were classified as lactose malabsorbers if a $\mathrm{H}_{2}$ and/or $\mathrm{CH}_{4}$ increase $>20 \mathrm{ppm}$ over the baseline value was observed within the colon passage 60-120 minutes after the lactose ingestion $[6,21]$. If lactose malabsorption was accompanied by gastrointestinal symptoms, patients were classified as lactose intolerant. Lactosedependent SIBO was considered if an increase of $>20 \mathrm{H}_{2}$ and/or $\mathrm{CH}_{4}$ above the baseline was observed up to 60 minutes after lactose ingestion [6]. A non- $\mathrm{H}_{2}$ producer status was defined as a $\mathrm{H}_{2}$ production $<5 \mathrm{ppm}$.

2.4. Genetic Test. In 2005 a genetic test method was established at the Department of Laboratory Medicine in the Central Hospital Steyr. Ethylenediaminetetraacetic acid (EDTA) blood samples were drawn from patients and stored at $-20^{\circ} \mathrm{C}$ for later deoxyribonucleic acid (DNA) preparation. The DNA was purified from EDTA blood $(200 \mu \mathrm{L})$ on the MagNA Pure Compact Instrument (Roche Diagnostics, Rotkreuz, Switzerland) using the MagNA Pure Compact Nucleic Acid Isolation Kit I (Roche Diagnostics, Rotkreuz, Switzerland) according to the manufacturer's instructions. Real-time PCR with specific fluorescent labeled hybridization probes, followed by melting curve analysis for detecting the LCT $\mathrm{C} / \mathrm{T}_{-13910}$ polymorphism, was performed on the LightCycler 1.1 Instrument (3-channel carousel based system; software version 3.5.3; Roche Diagnostics, Rotkreuz, Switzerland) [10, 21].

2.5. Statistics. Agreement between the combined $\mathrm{H}_{2} / \mathrm{CH}_{4}$ breath test and the genetic test was calculated using Cohen's Kappa. According to the literature [10], the lactose breath test was considered as the gold standard method. Sensitivity, specificity, and positive and negative predictive values of the genetic test $\left(\mathrm{C} / \mathrm{T}_{-13910}\right.$ polymorphism) were calculated compared to the $\mathrm{H}_{2} / \mathrm{CH}_{4}$ breath test.

\section{Results}

3.1. Patient Demographic Characteristics. In total 263 patients were included in this study. Of them 180 (68.4\%) were female and $83(31.6 \%)$ were male. The mean age was $42.5 \pm 19.18$.

3.2. Lactose $\mathrm{H}_{2} / \mathrm{CH}_{4}$ Breath Test (Table 1). Of all the included patients $(n=263), 24$ patients $(9.1 \%)$ showed an increase of $>20 \mathrm{H}_{2}$ and/or $\mathrm{CH}_{4}$ above the baseline value within the colon passage (60-120 minutes). All in all 21 patients $(8 \%)$ had a positive $\mathrm{H}_{2}$ breath test, 2 patients $(0.7 \%)$ had a positive $\mathrm{CH}_{4}$ breath test, and 1 patient $(0.4 \%)$ had a combined positive $\mathrm{H}_{2} / \mathrm{CH}_{4}$ breath test. In total 16 patients $(6.1 \%)$ with reported gastrointestinal symptoms were classified as lactose intolerant; eight patients (3\%) with a lack of clinical symptoms 
TABLE 2: Lactose $\mathrm{H}_{2} / \mathrm{CH}_{4}$ breath test versus genetic test $\left(\mathrm{C} / \mathrm{T}_{-13910}\right.$ polymorphism) results.

\begin{tabular}{lcc}
\hline & \multicolumn{2}{c}{$n=263$} \\
& $\mathrm{H}_{2} / \mathrm{CH}_{4}$ breath test $^{+}$ & $\mathrm{H}_{2} / \mathrm{CH}_{4}$ breath test $^{-}$ \\
\hline $\mathrm{C} / \mathrm{C}_{-13910}$ & $19(7.2 \%)$ & $32(12.2 \%)$ \\
$\mathrm{C} / \mathrm{T}_{-13910}$ & $4(1.5 \%)$ & $132(50.19 \%)$ \\
$\mathrm{T} / \mathrm{T}_{-13910}$ & $1(0.4 \%)$ & $75(28.51 \%)$ \\
\hline
\end{tabular}

+: $>20$ parts per million above baseline during the colon passage (60-120 minutes), - : negative.

TABLE 3: Reported symptoms during the lactose $\mathrm{H}_{2} / \mathrm{CH}_{4}$ breath test.

\begin{tabular}{lcc}
\hline & \multicolumn{3}{c}{$n=263$} \\
& $\mathrm{H}_{2} / \mathrm{CH}_{4}$ breath test $^{+}$ & $\mathrm{H}_{2} / \mathrm{CH}_{4}$ breath test $^{-}$ \\
\hline Symptoms $^{+}$ & $16(6.1 \%)$ & $41(15.6 \%)$ \\
Symptoms $^{-}$ & $8(3 \%)$ & $198(75.3 \%)$ \\
\hline
\end{tabular}

+: $>20$ parts per million above baseline during the colon passage (60-120 minutes), - : negative.

were categorized as lactose malabsorbers. No patient had an increase $>20 \mathrm{H}_{2}$ and/or $\mathrm{CH}_{4}$ ppm above the baseline value anytime during recording.

3.3. Comparison between the $\mathrm{H}_{2} / \mathrm{CH}_{4}$ Breath Test and the Genetic Test (Table 2). All in all 51 patients $(19.4 \%)$ were $\mathrm{C} / \mathrm{C}_{-13910}$ homozygotes, the responsible genotype for primary lactose malabsorption. In total 136 patients $(51.69 \%)$ were $\mathrm{C} / \mathrm{T}_{-13910}$ heterozygotes, and 76 patients $(28.91 \%)$ were $\mathrm{T} / \mathrm{T}_{-13910}$ homozygotes, indicating lactase persistence. Cohen's Kappa for agreement between the $\mathrm{H}_{2} / \mathrm{CH}_{4}$ breath test and the genetic test was 0.44 . Considering the lactose breath test as the gold standard method [10], the sensitivity of the genetic test compared to the breath test was $79 \%$, the specificity was $87 \%$, the positive predictive value was $60 \%$, and the negative predictive value was $98 \%$. All in all 32 patients $(12.2 \%)$ with the $\mathrm{C} / \mathrm{C}_{-13910}$ genotype showed a negative $\mathrm{H}_{2} / \mathrm{CH}_{4}$ breath test result. Four patients (1.5\%) with the $\mathrm{C} / \mathrm{T}_{-13910}$ genotype and one patient $(0.4 \%)$ with the $\mathrm{T} / \mathrm{T}_{-13910}$ genotype had a positive $\mathrm{H}_{2} / \mathrm{CH}_{4}$ breath test result, indicating a secondary lactose malabsorption form. Of them three patients had SIBO, one patient had gastroenteritis, and one patient had colitis ulcerosa. In one patient no associated gastrointestinal disease could be found in the anamnesis.

3.4. $\mathrm{CH}_{4}$ Producers and Non- $\mathrm{H}_{2}$ Producers. In 6 patients (2.3\%), a $\mathrm{CH}_{4}>20 \mathrm{ppm}$ was measured during the $\mathrm{H}_{2} / \mathrm{CH}_{4}$ breath test; another 16 patients (6.1\%) showed a $\mathrm{CH}_{4}$ measurement $>10-20 \mathrm{ppm}$. In 95 patients $(36.1 \%)$, the $\mathrm{H}_{2}$ measurement was $<5 \mathrm{ppm}$ during the breath test. They were classified as non- $\mathrm{H}_{2}$ producers. Of these only one patient showed a $\mathrm{CH}_{4}$ measurement $>20 \mathrm{ppm}$; another four patients showed a $\mathrm{CH}_{4}$ measurement $>10-20 \mathrm{ppm}$.

3.5. Symptoms during the Lactose $\mathrm{H}_{2} / \mathrm{CH}_{4}$ Breath Test (Table 3). During the lactose $\mathrm{H}_{2} / \mathrm{CH}_{4}$ breath test, 57 patients (21.7\%) reported one or more symptoms. Of these abdominal pain was present in 26 patients (45.6\%), bloating in 13 patients (22.8\%), and diarrhea in 11 patients (19.2\%). All in all 15 patients (22.8\%) reported nausea, heart burn, malaise,
TABLE 4: Lactose-dependent SIBO.

\begin{tabular}{lcc}
\hline$n=20(7.6 \%)$ & $\mathrm{H}_{2}$ breath test & $\mathrm{CH}_{4}$ breath test \\
\hline$n=16(6.1 \%)$ & + & - \\
$n=4(1.5 \%)$ & - & + \\
\hline
\end{tabular}

SIBO: small intestinal bacterial overgrowth, $+:>20$ parts per million above baseline up to 60 minutes after lactose ingestion, -: negative.

and extraintestinal symptoms like headache or dizziness. As shown in Table 3,16 patients (6.1\%) with a positive $\mathrm{H}_{2} / \mathrm{CH}_{4}$ breath test reported one or more symptoms during the test: six patients reported abdominal pain, five patients bloating, four patients diarrhea, and five patients nausea, malaise, or headache. Furthermore 41 patients (15.6\%) with a negative $\mathrm{H}_{2} / \mathrm{CH}_{4}$ breath test result reported one or more symptoms: twenty patients reported abdominal pain, seven patients bloating, seven patients diarrhea, and ten patients nausea, heart burn, headache, or dizziness. In total 8 patients $(3 \%)$ with a positive and 198 patients $(75.3 \%)$ with a negative $\mathrm{H}_{2} / \mathrm{CH}_{4}$ breath test showed neither gastrointestinal nor extraintestinal symptoms during the breath test.

3.6. Lactose-Dependent SIBO (Table 4). All in all 20 patients (7.6\%) with an increase of $>20 \mathrm{H}_{2}$ and/or $\mathrm{CH}_{4}$ ppm above the baseline during the small intestine transit time (up to 60 minutes after lactose ingestion) were classified as patients with a lactose-dependent SIBO. As shown in Table 4, 16 patients $(6.1 \%)$ were found with a positive $\mathrm{H}_{2}$ breath test and 4 patients $(1.5 \%)$ with a positive $\mathrm{CH}_{4}$ test. No one presented a combined positive $\mathrm{H}_{2} / \mathrm{CH}_{4}$ breath test.

\section{Discussion}

In the present study, the agreement between the $\mathrm{H}_{2} / \mathrm{CH}_{4}$ breath test and the genetic test was only moderate with a Cohen Kappa of 0.44. In contrast previous studies have demonstrated an excellent agreement between the breath test and the genetic test based on the $\mathrm{C} / \mathrm{T}_{-13910}$ polymorphism [10-12]. Five patients (1.9\%) with a negative genetic test were found with a positive $\mathrm{H}_{2} / \mathrm{CH}_{4}$ breath test result. They were categorized as secondary lactose malabsorbers $[3,7]$, associated with SIBO, gastroenteritis, or colitis ulcerosa. In total 32 patients (12.2\%) were found with a positive genetic test and a false negative $\mathrm{H}_{2} / \mathrm{CH}_{4}$ breath test result. Various reasons can lead to false negative breath test results. First of all the $\mathrm{H}_{2} / \mathrm{CH}_{4}$ measurement with the breath test is user-related and depends on preanalytical factors. Poor patient preparation combined with daily changes in the outpatient clinic staff can be a major cause of false negative $\mathrm{H}_{2} / \mathrm{CH}_{4}$ measurements. The end-expiratory alveolar air sample is of importance for the reliability of the breath test. In addition extraintestinal influences such as hyperventilation and exercise can significantly reduce the concentration of the exhaled gases [22, 23]. The previous use of antibiotics may also be a cause of false negative breath tests [24]. Although patients who have completed antibiotic therapy were excluded for at least four weeks from the breath test in this study, alterations of the colonic bacterial flora cannot be completely ruled out. The colonic $\mathrm{pH}$ is considered to influence the breath test results. 
In individuals with carbohydrate malabsorption the colonic contents are often acidic. An acidic colonic microclimate may affect the magnitude of bacterial gas production in the colon and cause false negative breath test results $[25,26]$. Another major variable of the breath test is the orocecal transit time. Constitutional and environmental factors affecting the transit time might play an important role in the composition and activities of the colonic flora [27]. A longer orocecal transit time can cause false negative results because the test may be finished before a measurable $\mathrm{H}_{2} / \mathrm{CH}_{4}$ increase is established. If a slow transit time is suspected, additional readings after 150 and 180 minutes should be considered [6].

All in all 95 patients (36.1\%) were classified as non- $\mathrm{H}_{2}$ producers in the present study. Compared to a previous study of the Medical University Graz, the recognition of non- $\mathrm{H}_{2}$ producers was up to $20 \%$ of the tested subjects [28]. The $\mathrm{H}_{2}$ based breath test is considered to give false negative test results in about $5-15 \%$ mainly due to methane production. Therefore a combined $\mathrm{H}_{2} / \mathrm{CH}_{4}$ measurement is expected to improve the diagnosis of malabsorption syndromes and SIBO [29]. The present study results show that only one non- $\mathrm{H}_{2}$ producer $(0.4 \%)$ had a $\mathrm{CH}_{4}$ measurement $>20 \mathrm{ppm}$, another four non- $\mathrm{H}_{2}$ producers $(1.5 \%)$ a $\mathrm{CH}_{4}$ measurement $>10-20 \mathrm{ppm}$. The high number of non- $\mathrm{H}_{2}$ producers $(36.1 \%)$ compared to the low number of $\mathrm{CH}_{4}$ producers $(1.9 \%)$ is indicative for user-related preanalytical deviations such as handling the gas chromatography measurements or instructing the patients to exhale end-expiratory breath leading to false negative breath test results.

In humans Methanobrevibacter smithii is considered to be the major methanogen responsible for measurable $\mathrm{CH}_{4}$ during the breath test [30]. All healthy subjects may produce $\mathrm{CH}_{4}$ in various concentrations, but only above a thresholdlevel $\mathrm{CH}_{4}$ does appear in the breath [31]. $\mathrm{CH}_{4}$ is associated with a slow intestinal transit and constipation [32-35]. A combined $\mathrm{H}_{2} / \mathrm{CH}_{4}$ measurement is considered to improve the diagnosis of lactose intolerance $[20,35]$, but rarely a $\mathrm{CH}_{4}$ cutoff value for a positive $\mathrm{CH}_{4}$ breath test is proposed in the literature. According to a previous work [20], a $\mathrm{H}_{2}$ and/or a $\mathrm{CH}_{4}$ peak $>20$ ppm over the baseline value was defined as a positive breath test in this study. In another previous study $\mathrm{H}_{2}$ and $\mathrm{CH}_{4}$ producers were defined as an increase of $>12 \mathrm{H}_{2} \mathrm{ppm}$ above the baseline and a mean $\mathrm{CH}_{4}$ excretion of $2 \mathrm{ppm}$ [35]. A standardized cutoff value to define a $\mathrm{H}_{2}$ and/or a $\mathrm{CH}_{4}$ producer is still lacking.

In total 57 patients $(21.7 \%)$ reported one or more symptoms during the $\mathrm{H}_{2} / \mathrm{CH}_{4}$ breath test. Of these abdominal pain was present in 26 patients (45.6\%), bloating in 13 patients $(22.8 \%)$, and diarrhea in 11 patients $(19.2 \%)$. Lactose intolerance is defined as lactose malabsorption with gastrointestinal symptoms $[5,7]$. All in all 16 patients $(6.1 \%)$ with a positive $\mathrm{H}_{2} / \mathrm{CH}_{4}$ breath test and reported gastrointestinal symptoms were classified as lactose intolerant. Eight patients (3\%) with a positive $\mathrm{H}_{2} / \mathrm{CH}_{4}$ breath test result and a lack of clinical symptoms were categorized as lactose malabsorbers. The validity of the reported symptoms during the breath test is limited because the symptom recording and scoring is proposed not only during but also eight hours after the breath test $[3,4,14]$. Furthermore the subjective perception of symptoms that patients associate with lactose intolerance does not always indicate lactose malabsorption [36].

According to the literature [6], 20 patients (7.6\%) with a $\mathrm{H}_{2}$ and/or $\mathrm{CH}_{4}$ peak of $>20 \mathrm{ppm}$ above the baseline value during the small intestine transit time (up to 60 minutes after lactose ingestion) were classified as patients with a lactosedependent SIBO. It is difficult to define the true prevalence of SIBO because of many confounding factors influencing the breath test. The prevalence depends on the nature and the dose of sugar used [16]. Glucose or lactulose $\mathrm{H}_{2}$ breath tests are the most commonly used tests [18]. Uniform criteria for breath test interpretation have not been proposed yet [37]. The accuracy and validity of the lactose $\mathrm{H}_{2} / \mathrm{CH}_{4}$ breath test interpretation are limited because this method has not been standardized yet. There is little experience with $\mathrm{CH}_{4}$ and it is not clear if the $\mathrm{CH}_{4}$ production after sugar ingestion can be interpreted in the same way as the $\mathrm{H}_{2}$ production. In the present study four patients $(1.5 \%)$ with a positive $\mathrm{CH}_{4}$ peak within 60 minutes after lactose ingestion were classified as SIBO. All of them had a negative $\mathrm{H}_{2}$ breath test; two patients showed intestinal symptoms. Another variable of the breath test is the small intestine transit time. An accelerated or delayed transit time can cause false negative or positive results. The major problem of the diagnosis of SIBO is that no gold standard method has been established yet because the culture of bacteria has its own difficulties and limitations $[18,29]$.

The limitation of this study is the retrospective study design. Lactose was given in a dose of $50 \mathrm{~g}$. In a recent study $50 \mathrm{~g}$ lactose was considered as a nonphysiological dose for the breath test as compared to $25 \mathrm{~g}$ [38]. The $50 \mathrm{~g}$ lactose dose might have led to a false positive lactose $\mathrm{H}_{2} / \mathrm{CH}_{4}$ breath test result, which was considered as secondary lactose malabsorption. In patients with secondary lactose malabsorption, the lactose breath test was not repeated to verify the recovered enzymatic activity. The symptom recording during the breath test was not carried out with a standardized questionnaire. Additional readings after 150 and 180 minutes were not made. Lactulose or glucose breath tests were not performed to confirm the diagnosis of SIBO. Prospective studies are needed to define uniform criteria for the interpretation of the combined $\mathrm{H}_{2} / \mathrm{CH}_{4}$ breath test and to promote the standardization of this limited diagnostic tool.

\section{Conclusions}

The present results show a moderate agreement between the combined $\mathrm{H}_{2} / \mathrm{CH}_{4}$ lactose breath test and the genetic test $\left(\mathrm{C} / \mathrm{T}_{-13910}\right.$ polymorphism) in daily clinical practice. Secondary lactose malabsorption as well as the preanalytical limitations of the breath test procedure and patient preparation can cause discrepant results between both methods. In clinical routine the combined $\mathrm{H}_{2} / \mathrm{CH}_{4}$ breath test as well as the genetic test $\left(\mathrm{C} / \mathrm{T}_{-13910}\right.$ polymorphism) should be performed on the one hand to verify patients with a secondary lactose malabsorption and on the other hand to detect false negative breath test results. A standardization of the $\mathrm{H}_{2} / \mathrm{CH}_{4}$ breath test procedure and interpretation is urgently needed to 
improve the diagnosis of lactose malabsorption and lactosedependent SIBO.

\section{Conflict of Interests}

The authors declare that there is no conflict of interests regarding the publication of this paper.

\section{References}

[1] R. Mattar, D. F. de Campos Mazo, and F. J. Carrilho, "Lactose intolerance: diagnosis, genetic, and clinical factors," Clinical and Experimental Gastroenterology, vol. 5, pp. 113-121, 2012.

[2] E. Madry, E. Fidler, and J. Walkowiak, "Lactose intolerancecurrent state of knowledge," Acta Scientiarum Polonorum, Technologia Alimentaria, vol. 9, no. 3, pp. 343-350, 2010.

[3] P. Usai-Satta, M. Scarpa, F. Oppia, and F. Cabras, "Lactose malabsorption and intolerance: what should be the best clinical management?" World Journal of Gastrointestinal Pharmacology and Therapeutics, vol. 3, no. 3, pp. 29-33, 2012.

[4] Ø. Hovde and P. G. Farup, "A comparison of diagnostic tests for lactose malabsorption-which one is the best?" BMC Gastroenterology, vol. 9, article 82, 2009.

[5] B. Misselwitz, D. Pohl, H. Frühauf, M. Fried, S. R. Vavricka, and M. Fox, "Lactose malabsorption and intolerance: pathogenesis, diagnosis and treatment," United European Gastroenterology Journal, vol. 1, no. 3, pp. 151-159, 2013.

[6] A. Eisenmann, A. Amann, M. Said, B. Datta, and M. Ledochowski, "Implementation and interpretation of hydrogen breath tests," Journal of Breath Research, vol. 2, no. 4, Article ID 046002, 2008.

[7] B. Terjung and F. Lammert, "Lactose intolerance: new aspects of an old problem," Deutsche Medizinische Wochenschrift, vol. 132, no. 6, pp. 271-275, 2007.

[8] M. Kuokkanen, J. Kokkonen, N. S. Enattah et al., "Mutations in the translated region of the lactase gene (LCT) underlie congenital lactase deficiency," American Journal of Human Genetics, vol. 78, no. 2, pp. 339-344, 2006.

[9] N. S. Enattah, T. Sahi, E. Savilahti, J. D. Terwilliger, L. Peltonen, and I. Järvelä, "Identification of a variant associated with adulttype hypolactasia," Nature Genetics, vol. 30, no. 2, pp. 233-237, 2002.

[10] D. Pohl, E. Savarino, M. Hersberger et al., "Excellent agreement between genetic and hydrogen breath tests for lactase deficiency and the role of extended symptom assessment," British Journal of Nutrition, vol. 104, no. 6, pp. 900-907, 2010.

[11] C. Högenauer, H. F. Hammer, K. Mellitzer, W. Renner, G. J. Krejs, and H. Toplak, "Evaluation of a new DNA test compared with the lactose hydrogen breath test for the diagnosis of lactose non-persistence," European Journal of Gastroenterology and Hepatology, vol. 17, no. 3, pp. 371-376, 2005.

[12] M. Krawczyk, M. Wolska, S. Schwartz et al., "Concordance of genetic and breath tests for lactose intolerance in a tertiary referral centre," Journal of Gastrointestinal and Liver Diseases, vol. 17, no. 2, pp. 135-139, 2008.

[13] K. A. Gwee, "The hydrogen breath test: new uses for an old test," Journal of Neurogastroenterology and Motility, vol. 16, no. 3, pp. 228-229, 2010.

[14] A. Gasbarrini, G. R. Corazza, G. Gasbarrini et al., "Methodology and indications of $\mathrm{H} 2$-breath testing in gastrointestinal diseases: final statements from the 1st Rome consensus conference," Alimentary Pharmacology and Therapeutics, vol. 29, no. 1, pp. 32-33, 2009.

[15] U. C. Ghoshal, "How to interpret hydrogen breath tests," Journal of Neurogastroenterology and Motility, vol. 17, no. 3, pp. 312-317, 2011.

[16] A. H. Sachdev and M. Pimentel, "Gastrointestinal bacterial overgrowth: pathogenesis and clinical significance," Therapeutic Advances in Chronic Disease, vol. 4, no. 5, pp. 223-231, 2013.

[17] J. Bures, J. Cyrany, D. Kohoutova et al., "Small intestinal bacterial overgrowth syndrome," World Journal of Gastroenterology, vol. 16, no. 24, pp. 2978-2990, 2010.

[18] M. Simrén and P.-O. Stotzer, "Use and abuse of hydrogen breath tests," Gut, vol. 55, no. 3, pp. 297-303, 2006.

[19] M. Gugatschka, H. Dobnig, A. Fahrleitner-Pammer et al., "Molecularly-defined lactose malabsorption, milk consumption and anthropometric differences in adult males," QJM - Monthly Journal of the Association of Physicians, vol. 98, no. 12, pp. 857863, 2005.

[20] S. V. Rana, S. K. Sinha, S. Sharma, H. Kaur, D. K. Bhasin, and K. Singh, "Effect of predominant methanogenic flora on outcome of lactose hydrogen breath test in controls and irritable bowel syndrome patients of north India," Digestive Diseases and Sciences, vol. 54, no. 7, pp. 1550-1554, 2009.

[21] R. Stolba, E. Rezanka, U. Eckhard, and G. Wider, “Genotyping of the LCT (T/C-13910) polymorphism on the LightCycler using fluorescent hybridisation probes," LaboratoriumsMedizin, vol. 29, no. 3, pp. 194-197, 2005.

[22] D. G. Thompson, P. Binfield, A. De Belder, J. O’Brien, S. Warren, and M. Wilson, "Extra intestinal influences on exhaled breath hydrogen measurements during the investigation of gastrointestinal disease," Gut, vol. 26, no. 12, pp. 1349-1352, 1985.

[23] D. L. Payne, J. D. Welsh, and P. L. Claypool, "Breath hydrogen (H2) response to carbohydrate malabsorption after exercise," Journal of Laboratory and Clinical Medicine, vol. 102, no. 1, pp. 147-150, 1983.

[24] T. Gilat, H. BenHur, E. Gelman-Malachi, R. Terdiman, and Y. Peled, "Alterations of the colonic flora and their effect on the hydrogen breath test," Gut, vol. 19, no. 7, pp. 602-605, 1978.

[25] J. A. Perman, S. Modler, and A. C. Olson, "Role of $\mathrm{pH}$ in production of hydrogen from carbohydrates by colonic bacterial flora. Studies in vivo and in vitro," Journal of Clinical Investigation, vol. 67, no. 3, pp. 643-650, 1981.

[26] H. Vogelsang, P. Ferenci, S. Frotz, S. Meryn, and A. Gangl, "Acidic colonic microclimate-possible reason for false negative hydrogen breath tests," Gut, vol. 29, no. 1, pp. 21-26, 1988.

[27] L. El Oufir, B. Flourié, S. Bruley Des Varannes et al., "Relations between transit time, fermentation products, and hydrogen consuming flora in healthy humans," Gut, vol. 38, no. 6, pp. 870$877,1996$.

[28] H. F. Hammer, W. Petritsch, H. Pristautz, and G. J. Krejs, "Assessment of the influence of hydrogen nonexcretion on the usefulness of the hydrogen breath test and lactose tolerance test," Wiener Klinische Wochenschrift, vol. 108, no. 5, pp. 137-141, 1996.

[29] B. P. de Lacy Costello, M. Ledochowski, and N. M. Ratcliffe, "The importance of methane breath testing: a review," Journal of Breath Research, vol. 7, no. 2, Article ID 024001, 2013.

[30] G. Kim, F. Deepinder, W. Morales et al., "Methanobrevibacter smithii is the predominant methanogen in patients with constipation-predominant IBS and methane on breath," Digestive Diseases and Sciences, vol. 57, no. 12, pp. 3213-3218, 2012. 
[31] L. F. McKay, M. A. Eastwood, and W. G. Brydon, "Methane excretion in man-a study of breath, flatus, and faeces," Gut, vol. 26, no. 1, pp. 69-74, 1985.

[32] M. Pimentel, H. C. Lin, P. Enayati et al., "Methane, a gas produced by enteric bacteria, slows intestinal transit and augments small intestinal contractile activity," American Journal of Physiology-Gastrointestinal and Liver Physiology, vol. 290, no. 6, pp. G1089-G1095, 2006.

[33] A. B. Sahakian, S.-R. Jee, and M. Pimentel, "Methane and the gastrointestinal tract," Digestive Diseases and Sciences, vol. 55, no. 8, pp. 2135-2143, 2010.

[34] D. Kunkel, R. J. Basseri, M. D. Makhani, K. Chong, C. Chang, and M. Pimentel, "Methane on breath testing is associated with constipation: a systematic review and meta-analysis," Digestive Diseases and Sciences, vol. 56, no. 6, pp. 1612-1618, 2011.

[35] M. Furnari, E. Savarino, L. Bruzzone et al., "Reassessment of the role of methane production between irritable bowel syndrome and functional constipation," Journal of Gastrointestinal and Liver Diseases, vol. 21, no. 2, pp. 157-163, 2012.

[36] F. Casellas, A. Aparici, M. Casaus, P. Rodríguez, and J. R. Malagelada, "Subjective perception of lactose intolerance does not always indicate lactose malabsorption," Clinical Gastroenterology and Hepatology, vol. 8, no. 7, pp. 581-586, 2010.

[37] C. S. Mello, S. Tahan, L. C. Melli et al., "Methane production and small intestinal bacterial overgrowth in children living in a slum," World Journal of Gastroenterology, vol. 18, no. 41, pp. 5932-5939, 2012.

[38] U. C. Ghoshal, S. Kumar, A. Misra, and B. Mittal, "Lactose malabsorption diagnosed by 50 -g dose is inferior to assess clinical intolerance and to predict response to milk withdrawal than 25 -g dose in an endemic area," Journal of Gastroenterology and Hepatology, vol. 28, no. 9, pp. 1462-1468, 2013. 


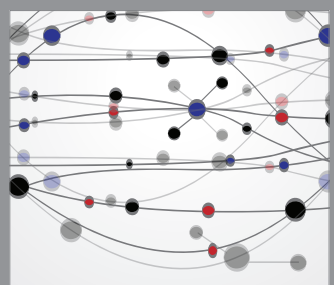

The Scientific World Journal
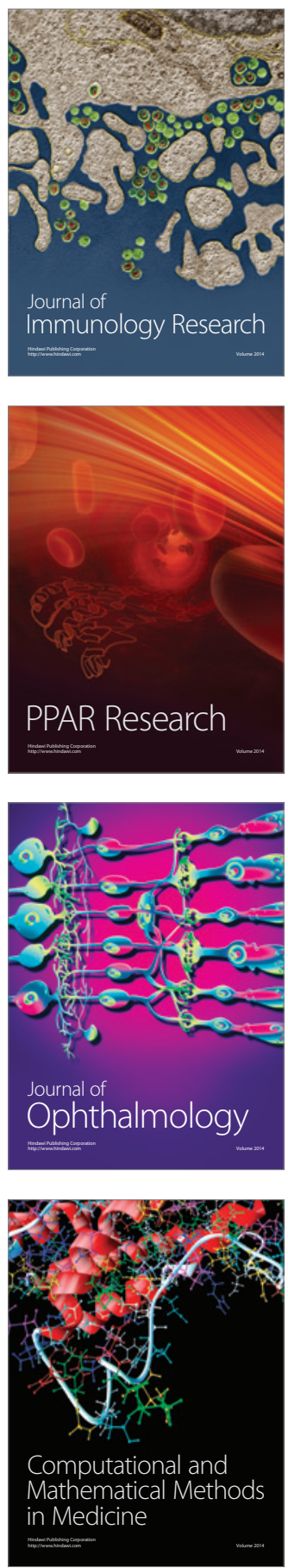

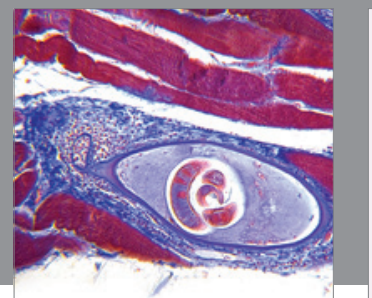

Gastroenterology

Research and Practice
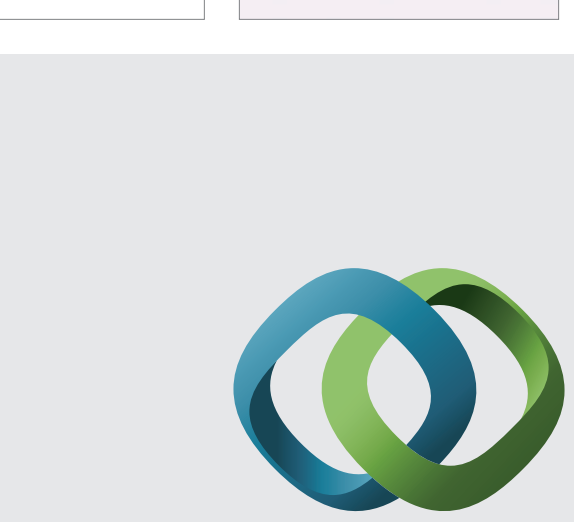

\section{Hindawi}

Submit your manuscripts at

http://www.hindawi.com
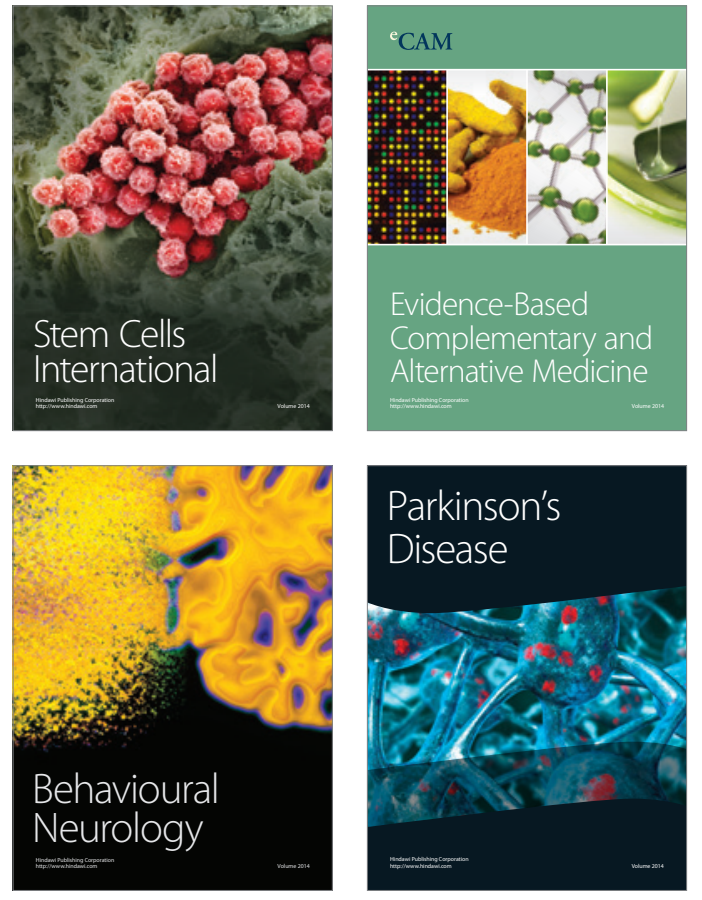
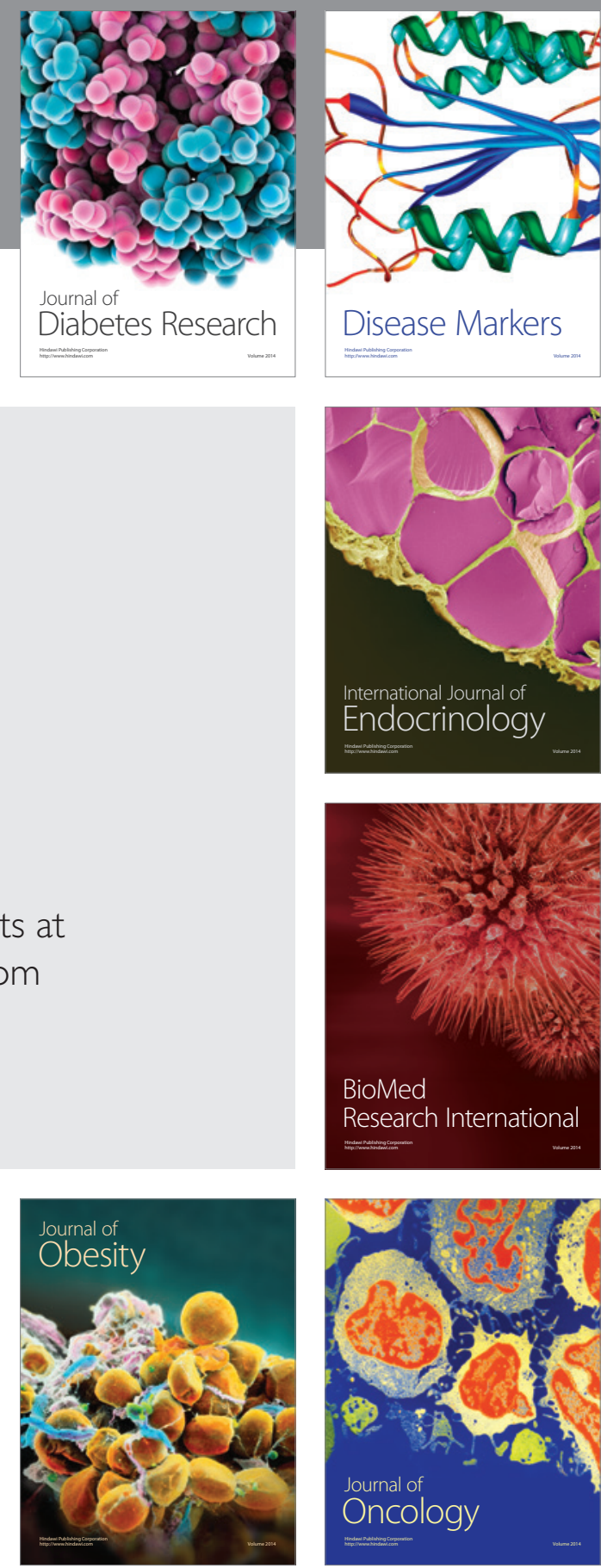

Disease Markers
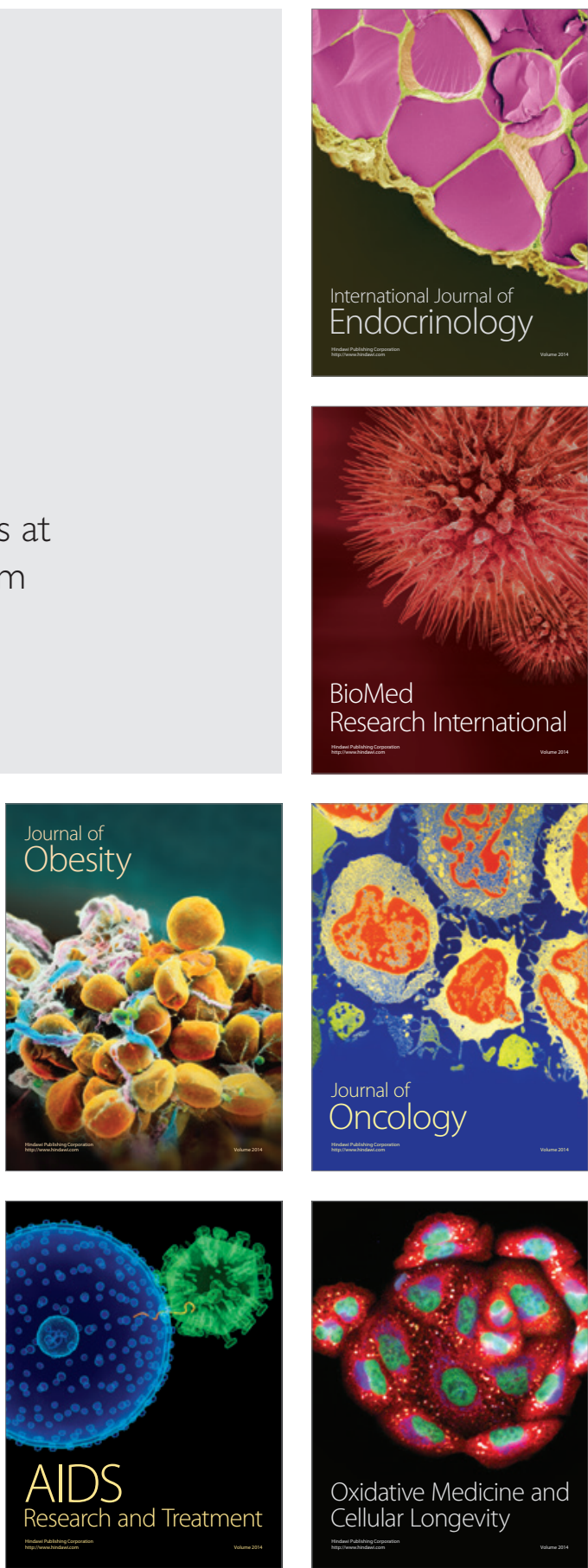